\title{
The effect of the position of stimulus cueing on short-term memory
}

CHARLES D. CORMAN ${ }^{1}$, WILBER D. BOSTIC ANO DELOS D. WICKENS THE OHIO STATE UNIVERSITY

Ss were presented with two potential items on each of a series of STM trials. On some trials, Ss knew which item was to be recalled before item presentation; on other trials, they did not. Although the procedure precluded rehearsal, prior knowledge of which item was to be recalled facilitated that recall. Ss' reports indicated this knowledge was utilized through the association of the to-be-remembered item with an "encoder."

When Ss know that material they are encountering must be recalled, that recall is facilitated. This is illustrated by the superiority of "intentional" learning over "incidental" learning (for a summary of numerous studies, see Postman, 1964). It is not clear how this knowledge leads to superior retention. It may be that Ss fail to attend to material that they believe they will not have to recall and that this reduces interference for the to-be-remembered material. It is also possible that Ss engage in behavior at the time of, or subsequent to, presentation of the to-be-remembered material that either strengthens the degree of learning or perhaps even bridges the retention interval. Rehearsal, either overt or covert, would be such behavior.

The present experiment involves the presentation of items of verbal material, some of which must be recalled. On all trials, one of two potential items must be recalled. On some trials, the $S$ knows which item must be recalled at the time the items are presented, on other trials, he does not. The procedure is designed to insure that the $\mathrm{S}$ will attend to both potential items, even when he is aware which item is extraneous. Further, the procedure is designed to keep the $S$ verbally active during the retention interval and thus preclude rehearsal. A previous experiment (Corman \& Wickens, in press) had indicated that the procedure did preclude rehearsal.

\section{Method}

Subjects. The Ss were 48 college students, both male and female, who chose to participate in the experiment in partial fulfillment of a laboratory requirement of an introductory psychology course. Six Ss were excused from the experiment because of equipment malfunction or failure to follow the prescribed procedure.

Apparatus. Verbal material was presented aurally by means of a tape recorder and Willson soundbarrier earphones. A panel in front of the $\mathbf{S}$ held two lights labelled " 1 " and "2" and differing in color. Either of the two lights could be illuminated by the $\mathrm{E}$ by means of a switch and push button. The panel was approximately $2 \mathrm{ft}$. in front of the $\mathrm{S}$ and the lights were 6 in. apart.
The experimental room was dimly illuminated and the $\mathrm{E}$ was seated out of the S's field of vision.

Procedure. Each $\mathrm{S}$ was presented with 18 series of numbers and letters. The $S$ was instructed to repeat each letter and number as he heard it and, as soon as the series ended, to recall the "cued" group of letters. Each series contained two consonant trigrams embedded in a series of numbers. The speaker said "ready" just before the series began and "recall" at the end of the series. (A typical series was of the form: "ready 438 S P T 24 N R X 6823694716 recall.") The elements in the series were presented at a rate of one every $2 / 3 \mathrm{sec}$. Thus the retention interval was approximately 12 sec. if the first trigram was cued and approximately $10 \mathrm{sec}$. if the second trigram was cued. The $S$ was permitted $10 \mathrm{sec}$. to recall the item after the end of the series and the inter-series (or intertrial) interval was 50 sec. $E$ recorded all responses of $S$ during the recall interval. A response was scored as correct if all three consonants were recalled, in any order. Cueing of the to-be-remembered trigram was done by means of the two lights in front of $S$. If $S$ was to recall the first trigram, the left light was illuminated, showing the numeral " 1. " If he was to recall the second trigram in the series, the other light was illuminated, showing the numeral "2." Each S was "pre-stimulus" cued (cue given when the speaker said "ready") for six consecutive trials, "post-stimulus" cued (cue given when the speaker said "recall") for six consecutive trials, and both pre-stimulus and post-stimulus cued for six consecutive trials. The order of the cueing procedures was counterbalanced across Ss and each series and to-be-remembered trigram occurred under each cueing procedure for an equal number of Ss. At the conclusion of each experimental session, E asked $S$ whether he had been able to "repeat the to-be-remembered letters to himself" and what technique, if any, he had used to help him remember.

\section{Results and Discussion}

The percentages of items correct following each of the cueing procedures were: pre-stimulus cued, $55.5 \%$; preand post-stimulus cued, $54.3 \%$, and post-stimulus cued, $21.2 \%$. ANOV shows a significant treatment effect $(F=$ 39.95, df $=2 / 82, p<.01$ ). Duncan's New Multiple Range Test indicates that the difference between pre-stimulus cueing and pre- and post-stimulus cueing was not significant, but both procedures produced better recall than post-stimulus cueing ( $p<.001)$.

There were two basic ways in which the $S$ could err. First, he could fail to recall the required number of 
Table 1. Frequency of Types of Errors following the Various Cueing Procedures

\begin{tabular}{lccc} 
Error Source & \multicolumn{3}{c}{ Cueing Procedures } \\
\hline & Pre-Stimulus & Pre- and Post- & Post- \\
\hline Pmissions & 44 & 74 & 116 \\
Intra-Series Intrusions & 81 & 79 & 170 \\
Extra-Series Intrusions & 57 & 51 & 89 \\
\hline
\end{tabular}

consonants, or perhaps no consonants at all. This failure to respond produced omissions. Second, he could give one or more inappropriate consonants or vowels. This produced intrusions. Intrusions can be further classified into intrusions which match the consonants in the irrelevant trigram, or "intra-series intrusions," and into "extra-series intrusions" of letters not contained in that series. Table 1 shows an analysis of omissions and intrusions as sources of error. These results suggest that interference between the consonants of the two trigrams in each series represents the major source of error, even when $\mathrm{S}$ knows a trigram is extraneous at the time of its presentation.

The results of this study indicate that awareness of which of the two verbal items must be recalled facili- tates recall even when $S$ is forced to attend to the extraneous and potentially interfering item. Questioning of $\mathrm{Ss}$ at the end of the experimental sessions indicated that no $S$ had been able to rehearse the to-be-remembered item during the retention interval. The most common strategy which $S$ reported was to associate the tobe-remembered item with some unit of meaningful material. This procedure is not unlike the mnemonic devices used to supplement rote memorization. These mediating units have been called "encoders." It is surprising that this technique can be utilized in such short intervals of time. According to the Ss, the ability to do so depended upon the prior knowledge as to which item should be mediated. These results suggest that the special quality of intentional learning may lie in the behavior of the $S$ in response to the to-be-remembered stimulus.

\section{References}

Corman, C. D., \& Wickens, D. D. Retroactive inhibition in shortterm memory. J.. verbal Learn. verbal Behav., in press.

Postman, L. J. Short-term memory and incidental learning. In A. W. Melton (Ed.), Categories of human learning. New York: Academic Press, 1964.

\section{Note}

1. Now at the University of Southern California. 